\title{
MiR-146a rs2910164 G/C polymorphism and gastric cancer susceptibility: a meta-analysis
}

\author{
Zhong $\mathrm{Xu}^{1+}$, Lingling Zhang ${ }^{1+}$, Hui $\mathrm{CaO}^{2^{*}}$ and Banjun Bai
}

\begin{abstract}
Background: Evidence has shown that single nucleotide polymorphism located in pre-miRNA or mature microRNA may modify various biological processes and affect the processing of carcinogenesis. Published results about the association between miR-146a rs2910164 G/C polymorphism and human gastric cancer susceptibility are inconclusive. The aim of this study was to acquire a more precise effect of the association between the miR-146a rs2910164 polymorphism and gastric risk by meta-analysis.

Methods: Eligible genetic association studies were searched from PubMed, Web of Knowledge and Chinese Biomedicine Database on human subject. Quantitative data synthesis was conducted for the associations of miR-146a rs2910164 G/C polymorphism with susceptibility to gastric cancer.

Results: Nine eligible studies that included a total of 3,885 gastric cancer patients and 5,396 controls were identified in the present meta-analysis. The overall OR indicated a potential association between rs2910164 polymorphism and GC but the effect was not statistically significant (GG vs. CG/CC: OR $=1.076,95 \%$ Cl 0.925-1.251, $P=0.342$ ). When stratifying for population, the result showed that miR-146a rs2910164 GG genotype was associated with increased gastric cancer risk among Chinese in recessive model (GG vs. CG/CC: OR $=1.171,95 \% \mathrm{Cl} 1.050-1.306$, $P=0.005)$. Besides, no significant difference was found in gender, smoking, location, metastasis of lymph node and Laurèn's classification.
\end{abstract}

Conclusions: The present meta-analysis suggests an increased risk between miR-146a rs2910164 GG genotype and gastric cancer susceptibility in Chinese based on published literatures.

Keywords: microRNA-146a, Stomach neoplasms, Polymorphism, Meta-analysis

\section{Background}

Gastric cancer (GC) is still one of the most common causes of cancer-related death worldwide despite an overall decrease in incidence over the past 10 years [1,2]. It is generally accepted that individual genetic susceptibility has an important role in the pathogenesis of tumor including GC.

MicroRNAs (miRNAs/miR) are endogenous 18-24 nucleotide noncoding RNAs that could regulate gene expression and sequentially regulate various biological processes [3,4]. Functional characterization of some microRNAs in cancer initiation and progression indicates that

\footnotetext{
* Correspondence: caohui912@hotmail.com

${ }^{\dagger}$ Equal contributors

2Department of Oncology, Guizhou Provincial People's Hospital, The Affiliated People's Hospital of Guiyang Medical University, Guiyang 550002, Guizhou Province, PR of China

Full list of author information is available at the end of the article
}

they might play a more important role in the pathogenesis of human cancers $[5,6]$. The relationship between miRNA and cancer has been extensively studied since 2002, the first demonstration of a link between miRNA genes and cancer [7].

Studies have shown that the polymorphisms in premiRNA or mature microRNA may modify various biological processes by influencing the expression and/or target selection of microRNAs [8,9]. Over the past decade, numerous studies identified genetic variants in the precursor or mature miRNA sequence of miR-146a rs2910164 ( $\mathrm{G}>\mathrm{C})$, which have been reported to be associated with breast cancer and hepatocellular carcinoma $[10,11]$.

A number of studies were published to describe the association between miR-146a rs2910164 G/C polymorphism and cancer risk in recent years. A meta-analysis 
reported by Lian et al. [10] concluded that the CC homozygote of rs2910164 may contribute to breast cancer susceptibility among Europeans. Another meta-analysis demonstrated that there is no significant correlation between has-miR-146a rs2910164 polymorphism and breast cancer risk [12]. A HuGE meta-analysis in 2013 failed to find any significant association between rs2910164 polymorphism and the risk of breast cancer [13]. Based on systematic review, Chen et al. [14] reported that quality of evidence was low for rs2910164 SNP genetic association with lung cancer. Several meta-analyses pooled the association between rs2910164 polymorphism and cancer risk in general [15,16]. Some meta-analysis reported the rs2910164 polymorphism and gastrointestinal cancer susceptibility [17-19].
However, published data on the association between miR-146a rs2910164 G/C polymorphism and human gastric cancer susceptibility are inconsistent and inconclusive. Therefore, we performed the present meta-analysis to quantitatively estimate the association of miR-146a G/C SNP with gastric cancer risks.

\section{Methods}

\section{Literature search strategy}

Electronic databases including PubMed, Web of Knowledge and Chinese Biomedicine Database (CBM) were searched for relevant studies conducted on human subject until July 2014. The following search keywords were used: "gastric" or "stomach", "neoplasm" OR "carcinoma" OR "cancer" OR "tumor" OR "adenocarcinoma" and "miR-146a OR

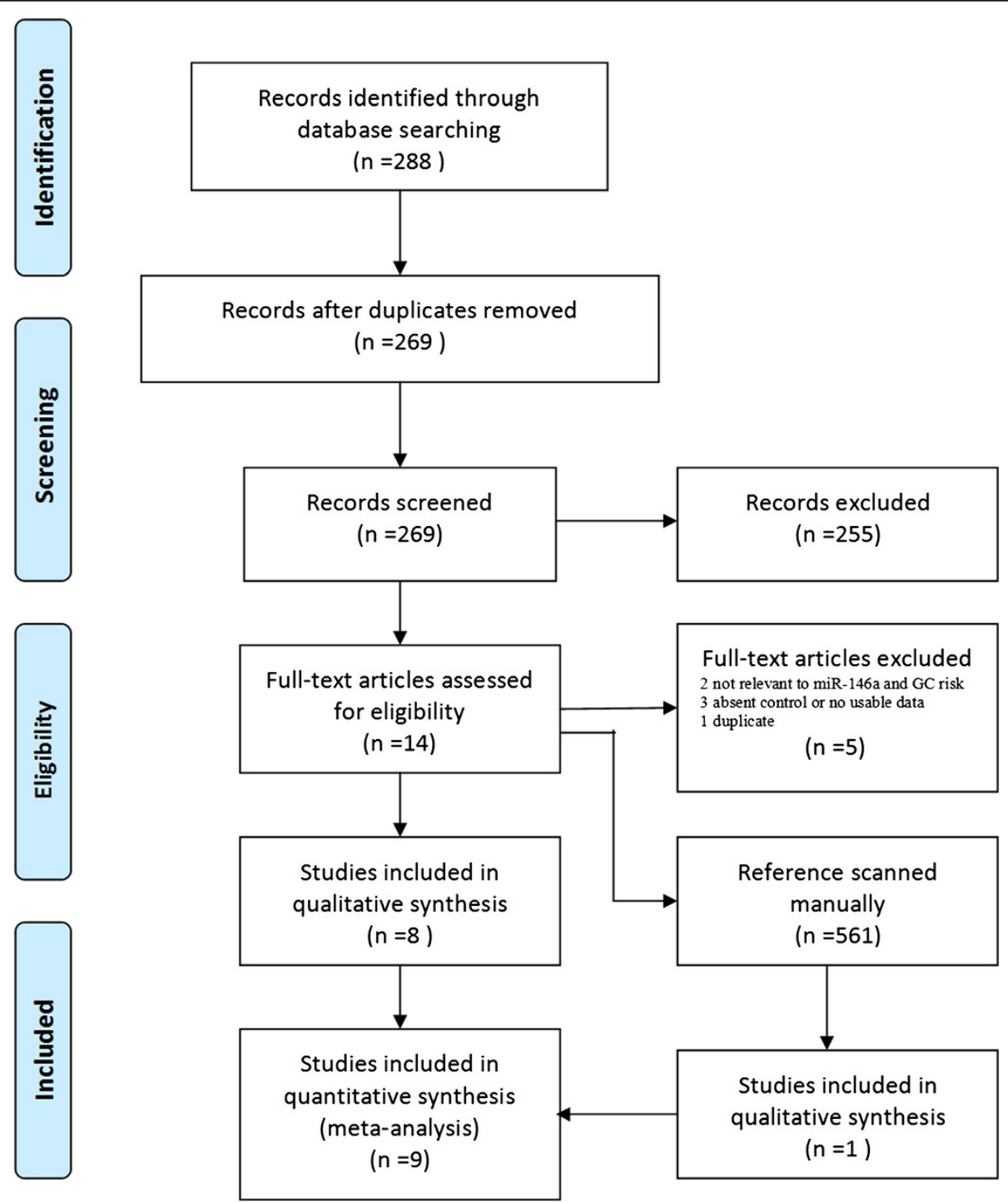

Figure 1 Flow chart of Studies inclusion and exclusion. 
Table 1 Characteristics of studies included in the meta-analysis

\begin{tabular}{|c|c|c|c|c|c|c|c|c|c|c|c|c|}
\hline \multirow{2}{*}{$\begin{array}{l}\text { First } \\
\text { author }\end{array}$} & \multirow[t]{2}{*}{ Year } & \multirow[t]{2}{*}{ Location } & \multirow{2}{*}{$\begin{array}{l}\text { Genotyping } \\
\text { method }\end{array}$} & \multirow{2}{*}{$\begin{array}{l}\text { No. of } \\
\text { cases }\end{array}$} & \multirow{2}{*}{$\begin{array}{l}\text { No. of } \\
\text { controls }\end{array}$} & \multicolumn{3}{|c|}{ Cases } & \multicolumn{3}{|c|}{ Controls } & \multirow{2}{*}{$\begin{array}{l}P_{\text {HWE }} \text { fol } \\
\text { control }\end{array}$} \\
\hline & & & & & & $\mathrm{CC}$ & CG & GG & $\mathrm{CC}$ & CG & GG & \\
\hline Okubo & 2010 & Japan & PCR-RFLP & 552 & 697 & 236 & 243 & 73 & 254 & 322 & 121 & 0.2776 \\
\hline Zeng & 2010 & China & PCR-RFLP & 304 & 304 & 89 & 153 & 62 & 119 & 132 & 53 & 0.1223 \\
\hline Hishida & 2011 & Japan & PCR-CTPP & 583 & 1637 & 230 & 271 & 82 & 633 & 775 & 229 & 0.7381 \\
\hline Zhou F & 2012 & China & TaqMan MGB & 1686 & 1895 & 286 & 822 & 578 & 393 & 951 & 551 & 0.6407 \\
\hline Zhou Y & 2012 & China & Locus-specific PCR & 299 & 416 & 107 & 146 & 46 & 127 & 215 & 74 & 0.301 \\
\hline Ahn & 2013 & Korea & PCR-RFLP & 461 & 447 & 159 & 231 & 71 & 164 & 221 & 62 & 0.3618 \\
\hline Dikeakos & 2014 & Greece & PCR-RFLP & 163 & 480 & 105 & 45 & 13 & 307 & 149 & 24 & 0.2892 \\
\hline Kupcinskas & 2014 & Europe & Real Time-PCR & 362 & 347 & 16 & 94 & 252 & 16 & 108 & 223 & 0.5311 \\
\hline $\mathrm{Pu}$ & 2014 & China & PCR-RFLP & 197 & 513 & 65 & 96 & 36 & 143 & 274 & 96 & 0.0801 \\
\hline
\end{tabular}

"miRNA-146a" OR "microRNA-146a" OR "has-miR$146 a$ ". To further identify potentially relevant studies, the reference lists of articles identified in the initial search were also scanned manually. We directly contacted authors for related data that were unavailable in the original publications.

\section{Inclusion and exclusion criteria}

Studies were considered eligible if they met all of the following criteria: (1) explore the association between miR146 a polymorphism and human GC risk, (2) design as case-control studies, (3) identification of gastric cancer cases was confirmed histologically or pathologically. Studies were excluded based on any of the following reasons: (1) no sufficient data reported, (2) articles of letters, reviews, case reports, conference abstracts, editorials or expert opinion. If serial studies of the same population from the same research group were published, only the largest series were selected.

\section{Data extraction}

The final set of articles was assessed independently by two reviewers (Zhong $\mathrm{Xu}$ and Lingling Zhang) according to the inclusion criteria listed above. Disagreements were resolved by discussion. The following information was retrieved from each report: first author, publication year, study population, ethnicity, number of GC cases and controls, frequency of genotypes, and genotyping method.

\section{Statistical analysis}

Hardy-Weinberg equilibrium (HWE) status was examined by Pearson's goodness-of-fit $X^{2}$ test in each study

Table 2 Meta-analysis of miR-146a rs2910164 polymorphism with gastric cancer by population

\begin{tabular}{|c|c|c|c|c|c|c|}
\hline \multirow[t]{2}{*}{ Population } & \multirow[t]{2}{*}{ Comparison } & \multirow{2}{*}{$\begin{array}{l}\text { No. of } \\
\text { study }\end{array}$} & \multicolumn{2}{|l|}{ Test of association } & \multicolumn{2}{|c|}{ Test of heterogeneity } \\
\hline & & & OR $(95 \% \mathrm{Cl})$ & $P$ & $P$ (Q-test) & $I^{2}$ \\
\hline \multirow[t]{5}{*}{ Asian } & GG vs. CC & 7 & $1.016(0.780,1.324)$ & 0.906 & 0.000 & $75.2 \%$ \\
\hline & CG vs. CC & & $0.998(0.847,1.176)$ & 0.982 & 0.014 & $62.2 \%$ \\
\hline & $\begin{array}{l}C G / G G \\
\text { vs. CC }\end{array}$ & & $1.005(0.830,1.216)$ & 0.962 & 0.001 & $75.1 \%$ \\
\hline & GG vs. CG/CC & & $1.025(0.861,1.221)$ & 0.779 & 0.036 & $55.6 \%$ \\
\hline & G vs. C & & $1.006(0.877,1.153)$ & 0.935 & 0.000 & $78.7 \%$ \\
\hline \multirow[t]{5}{*}{ European } & GG vs. CC & & $1.331(0.802,2.210)$ & 0.269 & 0.512 & $0.0 \%$ \\
\hline & CG vs. CC & & $0.880(0.619,1.253)$ & 0.478 & 0.973 & $0.0 \%$ \\
\hline & CG/GG vs. CC & 2 & $0.994(0.716,1.380)$ & 0.971 & 0.875 & $0.0 \%$ \\
\hline & GG vs. CG/CC & & $1.326(0.995,1.767)$ & 0.054 & 0.512 & $0.0 \%$ \\
\hline & G vs. C & & $1.146(0.937,1.401)$ & 0.184 & 0.608 & $0.0 \%$ \\
\hline \multirow[t]{5}{*}{ Overall } & GG vs. CC & 9 & $1.056(0.836,1.334)$ & 0.649 & 0.001 & $68.1 \%$ \\
\hline & CG vs. CC & & $0.984(0.853,1.136)$ & 0.830 & 0.037 & $51.3 \%$ \\
\hline & CG/GG vs. CC & & $1.005(0.852,1.184)$ & 0.956 & 0.002 & $66.9 \%$ \\
\hline & GG vs. CG/CC & & $1.076(0.925,1.251)$ & 0.342 & 0.052 & $48.0 \%$ \\
\hline & G vs. C & & $1.028(0.914,1.155)$ & 0.648 & 0.000 & $72.5 \%$ \\
\hline
\end{tabular}




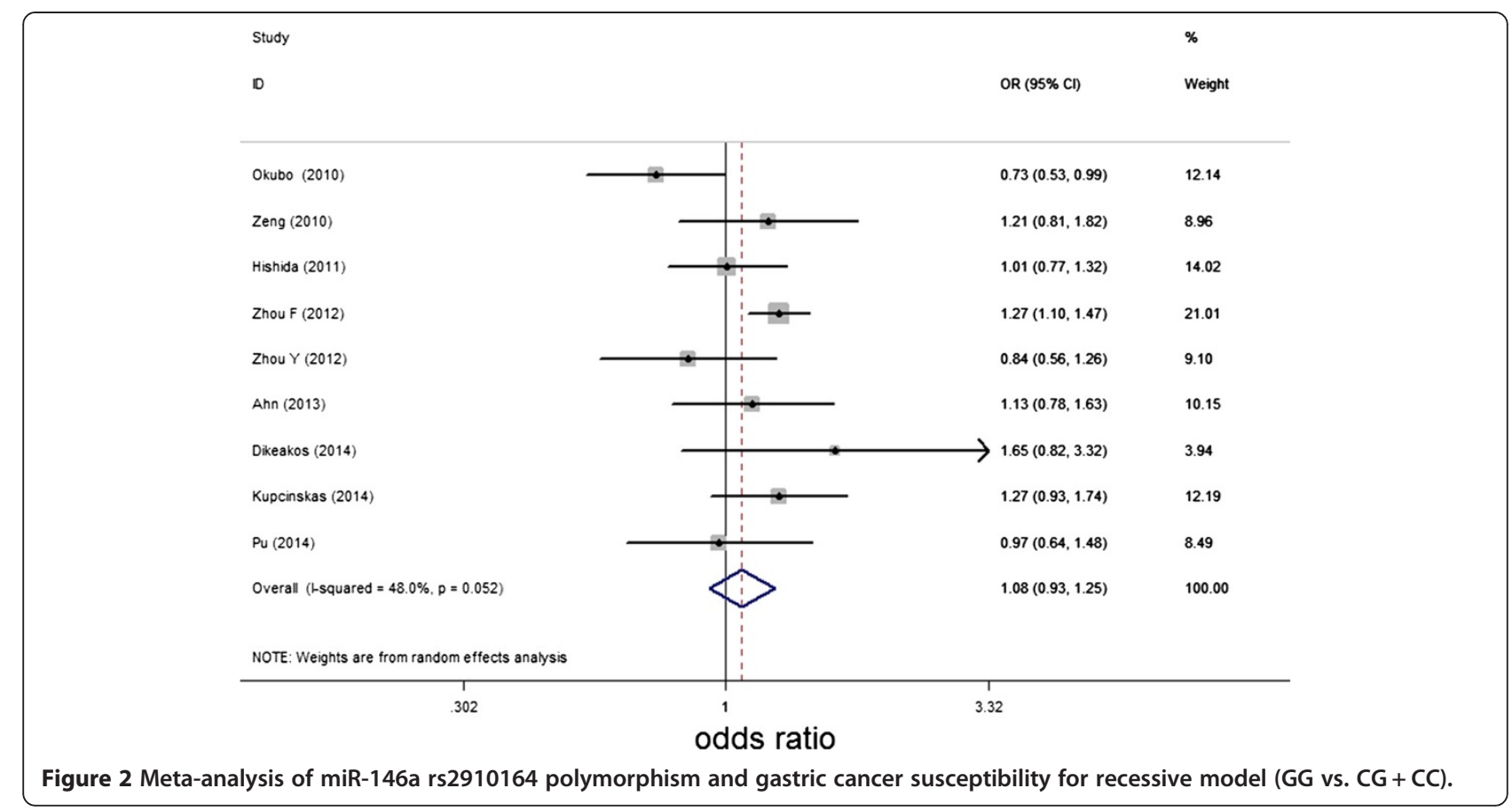

( $P<0.05$ was considered as significant disequilibrium in the control group). The strength of the association between GC and the miR-146a rs2910164 polymorphism was assessed by calculating odds ratio (OR) with 95\% confidence interval (CI). The pooled ORs were obtained from combination of single studies by homozygote comparison (GG vs. CC), heterozygote comparison (CG vs. $\mathrm{CC}$ ), dominant and recessive models (CG/GG vs. CC, and $\mathrm{GG}$ vs. $\mathrm{CG} / \mathrm{CC}$ ), allele comparison ( $\mathrm{G}$ vs. $\mathrm{C}$ ), respectively. The analysis of heterogeneity between studies was determined by using the Cochrane's Q test and $I^{2}$ test $\left(P<0.10\right.$ or $I^{2}>50 \%$ was considered indicative of statistically heterogeneity) [20]. When there was no significant heterogeneity existing among studies, the pooled ORs estimate of each study was calculated by the fixedeffects model. Otherwise, the random-effects model was employed. Subgroup analyses were stratified by the study characteristic if there were enough reports. Sensitivity analysis was carried out by deleting one single study each time to examine the influence of individual data set

Table 3 Meta-analysis of miR-146a rs2910164 polymorphism with gastric cancer in Chinese

\begin{tabular}{|c|c|c|c|c|}
\hline \multirow[t]{2}{*}{ Comparison } & \multicolumn{2}{|l|}{ Test of association } & \multicolumn{2}{|c|}{ Test of heterogeneity } \\
\hline & OR $(95 \% \mathrm{CI})$ & $P$ & $P$ (Q-test) & $I^{2}$ \\
\hline GG vs. CC & $1.113(0.773,1.604)$ & 0.564 & 0.011 & $73.1 \%$ \\
\hline CG vs. CC & $1.045(0.783,1.394)$ & 0.766 & 0.012 & $72.8 \%$ \\
\hline CG/GG vs. CC & $1.065(0.779,1.457)$ & 0.692 & 0.002 & $79.4 \%$ \\
\hline GG vs. CG/CC & $1.193(1.057,1.346)$ & 0.004 & 0.201 & $35.1 \%$ \\
\hline G vs. C & $1.055(0.868,1.283)$ & 0.590 & 0.004 & $77.8 \%$ \\
\hline
\end{tabular}

on the pooled ORs. Publication bias was assessed by using the methods of Begg's funnel plots and Egger's test $(P<0.05$ was considered representative of statistically significant publication bias) $[21,22]$. Statistical analyses performed by using the software Stata12.0 (Stata Corpotion, College Station, Texas).

\section{Results}

Studies selection and characteristics of the included studies

A total of 288 articles were identified from the PubMed, ISI and CBM database. The flow chart summarizes the literature review process as shown in Figure 1. A total of nine studies involving 3,885 GC cases and 5,396 controls were ultimately pooled for the present meta-analysis [23-31]. The characteristics of these studies are listed in Table 1. Among them, seven studies were performed in Asia (including patients from China, Japan and Korea), two studies in Europe (including patients from Greece, Germany, Lithuania and Latvia). Article by Okubo et al. [32] was excluded because of the duplication with another study [23]. All of the included articles were hospital-based case-control studies. The distribution of genotypes in the controls of all nine studies was in agreement with HWE.

\section{Quantitative data synthesis}

The summary of this meta-analysis for the association between miR-146a rs2910164 G/C polymorphism and the susceptibility of gastric cancer were shown in Table 2. Overall, there was no significant association 


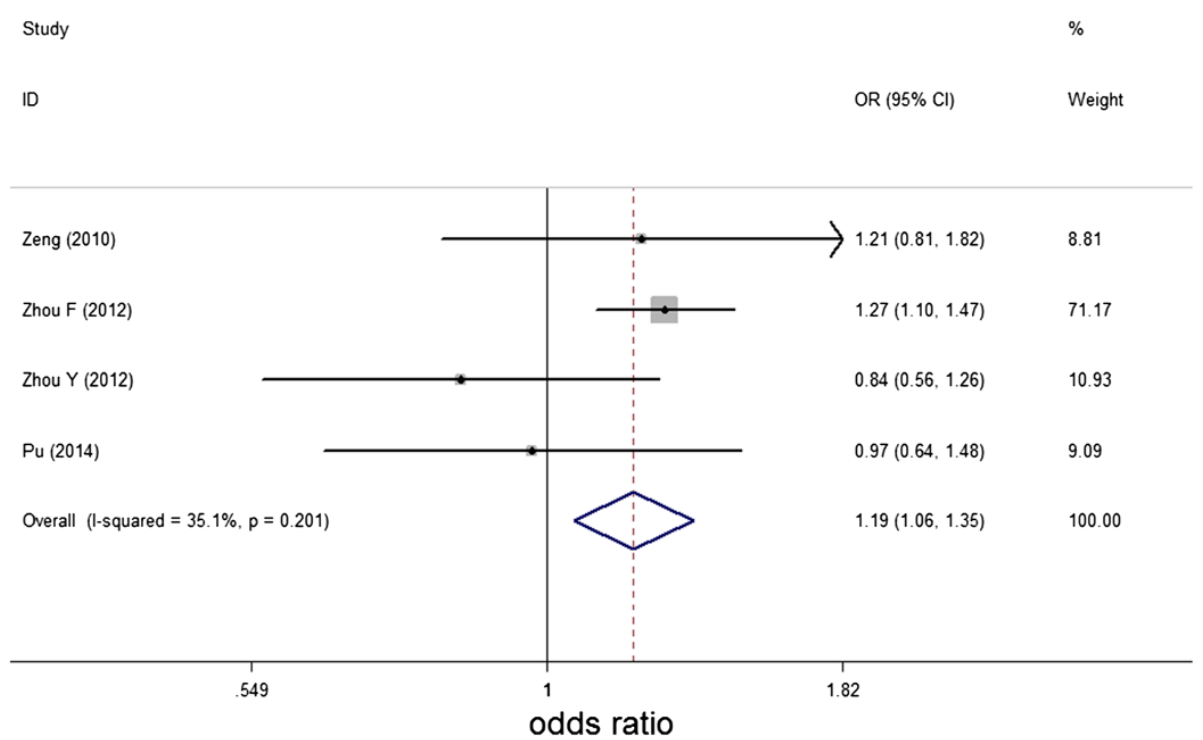

Figure 3 Meta-analysis of miR-146a rs2910164 polymorphism and gastric cancer susceptibility in Chinese for recessive model (GG vs. CG + CC).

in genotype distribution between gastric cancer and control by combining the nine studies. The randomeffects model was used to pool these results as statistically heterogeneity was observed between studies $\left(P\right.$ Q-test $\left.<0.1, I^{2}>50 \%\right)$. The pooled OR estimates of the meta-analyses were often greater than 1.00, indicating a potential association of rs2910164 polymorphism and GC although this effect was not statistically significant. For recessive model, as $P_{\mathrm{Q} \text {-test }}<0.1$ by heterogeneity analysis, also the random-effects model was used for analysis. As shown in Figure 2, there was no statistically increased risk of gastric cancer in recessive model when pooled the nine studies (recessive model, GG vs. CG/ CC: OR $=1.076,95 \%$ CI 0.925-1.251, $\mathrm{P}=0.342$ ).

However, as shown in Table 3 and Figure 3, when we performed subgroup analysis by location, the combined result showed that miR-146a rs2910164 GG genotype was associated with increased gastric cancer risk in China for recessive model (GG vs. CG/ CC: OR = $1.193,95 \%$ CI 1.057-1.346, $\mathrm{P}=0.004)$. In addition, interactions between miR-146a polymorphism and clinicopathological characters were also conducted when usable data obtained. No significant association between miR-146a genetic variant and gastric cancer risk were found in the stratified analysis by gender, smoking, location, metastasis of lymph node and Laurèn's classification (Table 4).

\section{Sensitivity analysis and publication bias}

We use one-way sensitivity analysis to evaluate the stability of the result in China [33]. In recessive model, the sensitivity analysis of pooled OR with $95 \% \mathrm{CI}$ changed from $1.193(1.057,1.346)$ to $0.995(0.786,1.260)$ when omitting one study by Zhou F [26] (Figure 4). The corresponding pooled OR was not materially altered in other genetic models.

Begg's funnel plot (Figure 5) and Egger's test (Figure 6) indicated no potential publication bias $(P=1.000$ and

Table 4 Meta-analysis of rs2910164 polymorphism with GC by Clinicopathological characters

\begin{tabular}{|c|c|c|c|c|c|c|}
\hline \multirow[t]{2}{*}{ Parameters } & \multirow[t]{2}{*}{ Comparison } & \multirow{2}{*}{$\begin{array}{l}\text { No. of } \\
\text { study }\end{array}$} & \multicolumn{2}{|l|}{ Test of association } & \multicolumn{2}{|c|}{ Test of heterogeneity } \\
\hline & & & OR $(95 \% \mathrm{Cl})$ & $P$ & $P(Q-$ test $)$ & $I^{2}$ \\
\hline Gender & CC vs. GG/CG & 4 & $0.916(0.691,1.215)$ & 0.542 & 0.201 & $37.7 \%$ \\
\hline (Male vs. Female) & CC/CG vs. GG & 4 & $0.939(0.767,1.148)$ & 0.538 & 0.967 & $0.0 \%$ \\
\hline Smoking (No vs. Yes) & CC vs. CG/GG & 2 & $0.843(0.554,1.282)$ & 0.425 & 0.315 & $0.9 \%$ \\
\hline \multirow[t]{2}{*}{ Site (Cardic vs. Non-Cardic) } & CC vs. CG/GG & 4 & $0.844(0.593,1.201)$ & 0.346 & 0.382 & $0.0 \%$ \\
\hline & CC/CG vs. GG & 4 & $0.897(0.738,1.090)$ & 0.274 & 0.549 & $0.0 \%$ \\
\hline Metastasis of lymph node (Negative vs. Positive) & CC vs. CG/GG & 2 & $1.211(0.842,1.742)$ & 0.302 & 0.589 & $0.0 \%$ \\
\hline Laurèn's classification (Intestinal vs. Diffuse) & CC/CG vs. GG & 4 & $0.961(0.807,1.145)$ & 0.658 & 0.655 & $0.0 \%$ \\
\hline
\end{tabular}




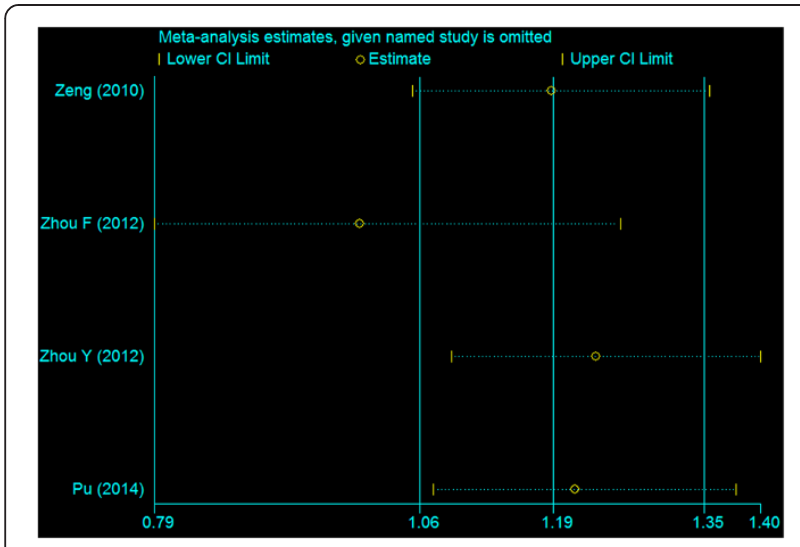

Figure $\mathbf{4}$ The influence of each study by omission of individual studies in China for recessive model.

0.355, respectively). The funnel plots showed some asymmetry, which is probably due to the limited number of studies.

\section{Discussion}

MiR-146a has been shown to play an important role in cell proliferation, differentiation, apoptosis and tumorigenesis [34-37]. Study by Jazdzewski et al. [38] in 2008 has suggested that rs2910164, a common polymorphism in the pre-miR-146a sequence, could alter mature miR146 a expression and play a role in the tumorigenesis. In the past three years, a number of meta-analyses and review pooled the association between rs2910164 G>C polymorphism and cancer risk including gastrointestinal tumors broadly [15-19,39-43]. Nine of them have evaluated the association between rs2910164 polymorphism and gastric cancer risk. With the same results, all of them concluded no significant association between rs2910164 polymorphism and gastric cancer.

Still why we performed this meta-analysis concerning the miR-146a polymorphism in gastric cancer susceptibility? Firstly, as shown in Table 5, the included studies

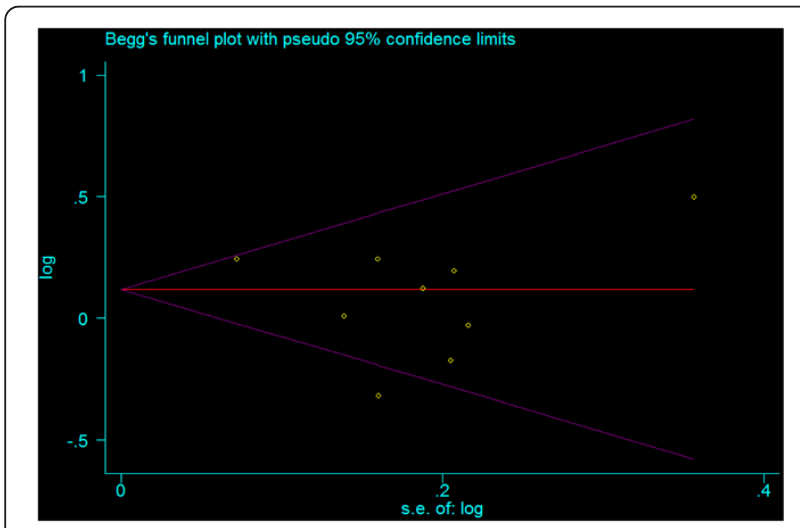

Figure 5 Begg's funnel plot with pseudo $95 \%$ confidence limits.

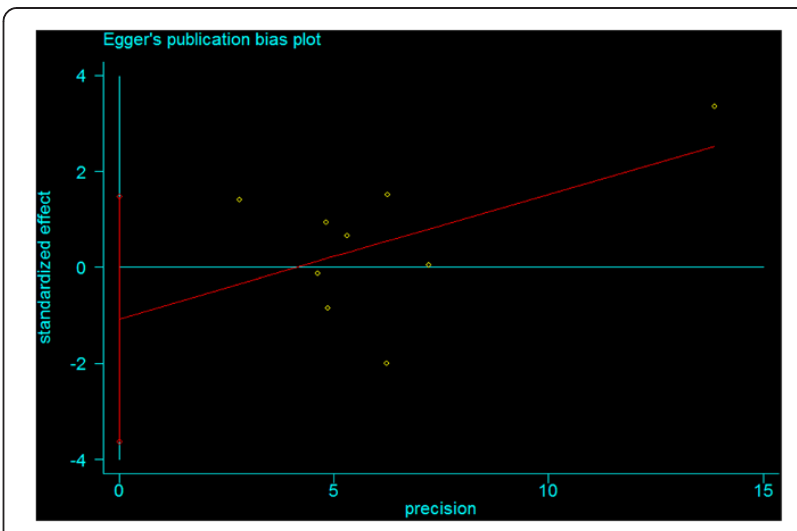

Figure 6 Egger's publication bias plot.

were limited in all of these meta-analyses regarding gastric cancer. All of them excluded the study by Zhou Y et al. [27] because of absence data in the article. Among them, meta-analysis by $\mathrm{Xu} \mathrm{X}$ et al. [19] included six researches $[23-26,28,44]$ to evaluate the association between rs2910164 polymorphism and gastric cancer risk. However, one of the six included articles detected rs2910164 polymorphism from gastritis [44], not gastric cancer. Then, none of the nine meta-analyses evaluated the miR146a rs2910164 G > C polymorphism and gastric cancer susceptibility in details. Moreover, it is general that esophageal cancer, liver cancer, gastric cancer, cervical cancer and other malignancies have too distinct molecular mechanisms and logically they do not seem to harbor a common polymorphism as a risk factor. Similarly, esophageal cancer, gastric cancer and colorectal cancer are not always consistent with each other in this term. Last but not least, an update is needed to evaluate the association between rs2910164 G > C polymorphism and gastric cancer risk. Therefore, we try to acquire a more precise assessment of the association between rs2910164 polymorphism and gastric risk.

Table 5 Meta-analyses of rs2910164 polymorphism and cancer risk (information about GC)

\begin{tabular}{llllllll}
\hline First author & Year & \multicolumn{5}{c}{ ncluded study about gastric cancer } \\
\cline { 3 - 8 } & & [24] & [25] & [26] & [28] & [23] & [44] \\
\hline Srivastava [15] & 2012 & $\sqrt{ }$ & $\sqrt{ }$ & $\sqrt{ }$ & $\sqrt{ }$ & \\
Wang J [16] & 2012 & $\sqrt{ }$ & $\sqrt{ }$ & & $\sqrt{ }$ & \\
Wang F [17] & 2012 & $\sqrt{ }$ & $\sqrt{ }$ & & & $\sqrt{ }$ & \\
Wu [18] & 2013 & $\sqrt{ }$ & $\sqrt{ }$ & & & $\sqrt{ }$ & \\
Xu X [19] & 2014 & $\sqrt{ }$ & $\sqrt{ }$ & $\sqrt{ }$ & $\sqrt{ }$ & $\sqrt{ }$ & $\sqrt{ }$ \\
Qiu [40] & 2011 & $\sqrt{ }$ & $\sqrt{ }$ & & & $\sqrt{ }$ & \\
He [41] & 2012 & $\sqrt{ }$ & $\sqrt{ }$ & $\sqrt{ }$ & & $\sqrt{ }$ & \\
Xu Y [42] & 2013 & $\sqrt{ }$ & $\sqrt{ }$ & $\sqrt{ }$ & & $\sqrt{ }$ & \\
Yin [43] & 2013 & $\sqrt{ }$ & $\sqrt{ }$ & $\sqrt{ }$ & & $\sqrt{ }$ & \\
\hline
\end{tabular}


Focused on rs2910164 SNP and gastric cancer, the present meta-analysis showed that the miR-146a GG genotype was associated with increased risk of gastric cancer in China subgroup in recessive model (pooled $\mathrm{OR}=1.193$ ). There were no significant differences in gender, smoking, location, metastasis of lymph node and Laurèn's classification across genotypes.

Of the nine studies included, studies by Zeng et al. [24] and Zhou F et al. [26] describe distribution of genotype in gastric cancer by age. The former demonstrated that rs2910164 GC/GG genotype had a increased risk of gastric cancer especially in younger individuals aged ( $\leq 58$ years), the later showed that GG genotype increased gastric cancer risk was more evident in younger subjects ( $\leq 65$ years). Zhou Y et al. [27] did not find any differennt distribution in gastric cancer between different tumor size $(<5 \mathrm{~cm}$ vs. $\geq 5 \mathrm{~cm})$. In addition, Zeng et al. [24] reported no statistically significant association in the variant genotypes with tumor differentiation. Almost all of included studies were conducted in Asia except two studies were in Europe. The study by Kupcinskas et al. in Europe [30] analyzed gene polymorphisms of miR-146a in 995 subjects including Germany, Latvia and Lithuania. Data analysis showed that gene polymorphisms of miR-146a are not associated with risk of GC in Europe. Besides, no difference between diffuse and intestinal-type gastric cancer groups was found.

The results should be interpreted with carefulness because of several limitations. First, the limited patient numbers may have influence the outcomes. Although we conducted comprehensive literature research from multiple databases with no restriction in publication languages, dates, ethnicities and other factors, there were only a total of nine studies involving 3,885 gastric cancer cases and 5,396 controls for the present meta-analysis. The overall OR indicated a potential association between rs2910164 polymorphism and GC but the effect was not statistically significant. It is still hard to make a firm conclusion about the accuracy of association between miR146a rs2910164 G > C polymorphism and gastric cancer susceptibility. Second, we use one-way sensitivity analysis to evaluate the stability of the meta-analysis and the result altered when omitting the study with the largest samples. Third, only a few included researches reported data of interactions between miR-146a polymorphism and clinicopathological characters in gastric cancer, and all of the pooled analysis of interactions was limited by small sample size and deficit of data.

\section{Conclusion}

In conclusion, the present meta-analysis suggests an increased risk between miR-146a rs2910164 GG genotype and gastric cancer susceptibility in Chinese based on published literatures. Further studies on a large scale may be needed to confirm the genetic susceptibility of miR-146a rs2910164 in gastric cancer.

\section{Competing interests}

The authors declare that they have no competing interests.

\section{Authors' contributions}

$X Z, Z L$, and $\mathrm{CH}$ participated in design and collect the literature data. $X Z$ and $\mathrm{CH}$ analyzed the data. $\mathrm{BB}$ guided the data extraction and analysis. $\mathrm{XZ}, \mathrm{ZL}, \mathrm{CH}$ and $\mathrm{BB}$ participated in write the manuscript. All authors read and approved the final manuscript.

\section{Acknowledgments}

This paper was supported by the Funds of Guizhou Provincial Department of Science and Technology, No.qiankehe-J-2012-2240.

We thanks Master Yuan Zhou for provide the related original data.

\section{Author details}

${ }^{1}$ Department of Gastroenterology, Guizhou Provincial People's Hospital, The Affiliated People's Hospital of Guiyang Medical University, Guiyang 550002, Guizhou Province, PR China. ²Department of Oncology, Guizhou Provincial People's Hospital, The Affiliated People's Hospital of Guiyang Medical University, Guiyang 550002, Guizhou Province, PR of China.

Received: 27 March 2014 Accepted: 10 October 2014

Published online: 20 October 2014

\section{References}

1. Siegel R, Naishadham D, Jemal A: Cancer statistics, 2013. CA Cancer J Clin 2013, 63:11-30.

2. Lin Y, Ueda J, Kikuchi S, Totsuka Y, Wei WQ, Qiao YL, Inoue M: Comparative epidemiology of gastric cancer between Japan and China. World J Gastroenterol 2011, 17:4421-4428

3. Bartel DP, Chen CZ: Micromanagers of gene expression: the potentially widespread influence of metazoan microRNAs. Nat Rev Genet 2004, 5:396-400.

4. Bartel DP: MicroRNAs: genomics, biogenesis, mechanism, and function. Cell 2004, 116:281-297.

5. Esquela-Kerscher A, Slack FJ: Oncomirs - microRNAs with a role in cancer. Nat Rev Cancer 2006, 6:259-269.

6. Costinean S, Zanesi N, Pekarsky Y, Tili E, Volinia S, Heerema N, Croce CM: Pre-B cell proliferation and lymphoblastic leukemia/high-grade lymphoma in E(mu)-miR155 transgenic mice. Proc Natl Acad Sci U S A 2006, 103:7024-7029.

7. Calin GA, Dumitru CD, Shimizu M, Bichi R, Zupo S, Noch E, Aldler H, Rattan S, Keating M, Rai K, Rassenti L, Kipps T, Negrini M, Bullrich F, Croce CM: Frequent deletions and down-regulation of micro- RNA genes miR15 and miR16 at 13q14 in chronic lymphocytic leukemia. Proc Natl Acad Sci U S A 2002, 99:15524-15529.

8. Saunders MA, Liang H, Li WH: Human polymorphism at microRNAs and microRNA target sites. Proc Natl Acad Sci U S A 2007, 104:3300-3305.

9. Iwai N, Naraba H: Polymorphisms in human pre-miRNAs. Biochem Biophys Res Commun 2005, 331:1439-1444.

10. Lian H, Wang L, Zhang J: Increased risk of breast cancer associated with CC genotype of Has-miR-146a Rs2910164 polymorphism in Europeans. PLoS One 2012, 7:e31615.

11. Xu Y, Li L, Xiang X, Wang H, Cai W, Xie J, Han Y, Bao S, Xie Q: Three common functional polymorphisms in microRNA encoding genes in the susceptibility to hepatocellular carcinoma: a systematic review and meta-analysis. Gene 2013, 527:584-593.

12. Gao LB, Bai P, Pan XM, Jia J, Li LJ, Liang WB, Tang M, Zhang LS, Wei YG, Zhang $L$ : The association between two polymorphisms in pre-miRNAs and breast cancer risk: a meta-analysis. Breast Cancer Res Treat 2011, 125:571-574.

13. Chen $\mathrm{QH}$, Wang $\mathrm{QB}$, Zhang B: Ethnicity modifies the association between functional microRNA polymorphisms and breast cancer risk: a HuGE meta-analysis. Tumour Biol 2013, 35:529-543.

14. Chen Z, Xu L, Ye X, Shen S, Li Z, Niu X, Lu S: Polymorphisms of microRNA sequences or binding sites and lung cancer: a meta-analysis and systematic review. PLoS One 2013, 8:e61008. 
15. Srivastava K, Srivastava A: Comprehensive review of genetic association studies and meta-analyses on miRNA polymorphisms and cancer risk. PLoS One 2012, 7:e50966.

16. Wang J, Wang Q, Liu H, Shao N, Tan B, Zhang G, Wang K, Jia Y, Ma W, Wang $N$, Cheng $Y$ : The association of miR-146a rs2910164 and miR-196a2 rs11614913 polymorphisms with cancer risk: a meta-analysis of 32 studies. Mutagenesis 2012, 27:779-788.

17. Wang F, Sun G, Zou Y, Fan L, Song B: Lack of association of miR-146a rs2910164 polymorphism with gastrointestinal cancers: evidence from 10206 subjects. PloS One 2012, 7:e39623.

18. Wu D, Wang F, Dai WQ, He L, Lu J, Xu L, Guo CY: The miR-146a rs2910164 $\mathrm{G}>\mathrm{C}$ polymorphism and susceptibility to digestive cancer in Chinese. Asian Pac J Cancer Prev 2013, 14:399-403.

19. Xu X, Yang $X, R u$ G, Wu Y, Zhang $S$, Xing C, Wu Y, Cao J: miR-146a gene polymorphism rs2910164 and the risk of digestive tumors: a metaanalysis of 21 case-control studies. Oncol Rep 2014, 31:472-479.

20. Higgins JP, Thompson SG: Quantifying heterogeneity in a meta-analysis. Stat Med 2002, 21:1539-1558.

21. Egger M, Davey Smith G, Schneider M, Minder C: Bias in meta-analysis detected by a simple, graphical test. BMJ (Clinical research ed) 1997, 315:629-634.

22. Begg CB, Mazumdar M: Operating characteristics of a rank correlation test for publication bias. Biometrics 1994, 50:1088-1101.

23. Okubo M, Tahara T, Shibata T, Yamashita H, Nakamura M, Yoshioka D, Yonemura J, Ishizuka T, Arisawa T, Hirata I: Association between common genetic variants in pre-microRNAs and gastric cancer risk in Japanese population. Helicobacter 2010, 15:524-531.

24. Zeng Y, Sun QM, Liu NN, Dong GH, Chen J, Yang L, Wang B: Correlation between pre-miR-146a C/G polymorphism and gastric cancer risk in Chinese population. World J Gastroenterol 2010, 16:3578-3583.

25. Hishida A, Matsuo K, Goto Y, Naito M, Wakai K, Tajima K, Hamajima N: Combined effect of miR-146a rs2910164 G/C polymorphism and Toll-like receptor $4+3725 \mathrm{G} / \mathrm{C}$ polymorphism on the risk of severe gastric atrophy in Japanese. Dig Dis Sci 2011, 56:1131-1137.

26. Zhou F, Zhu H, Luo D, Wang M, Dong X, Hong Y, Lu B, Zhou Y, Zhou J, Zhang Z, Gong W: A functional polymorphism in Pre-miR-146a is associated with susceptibility to gastric cancer in a Chinese population. DNA Cell Biol 2012, 31:1290-1295.

27. Zhou Y, Du WD, Chen G, Ruan J, Xu S, Zhou FS, Zuo XB, Lv ZJ, Zhang XJ: Association analysis of genetic variants in microRNA networks and gastric cancer risk in a Chinese Han population. J Cancer Res Clin Oncol 2012, 138:939-945.

28. Ahn DH, Rah H, Choi YK, Jeon YJ, Min KT, Kwack K, Hong SP, Hwang SG, Kim NK: Association of the miR-146aC > G, miR-149T > C, miR-196a2T > $C$, and miR-499A > G polymorphisms with gastric cancer risk and survival in the Korean population. Mol Carcinog 2013, 52:39-51.

29. Dikeakos P, Theodoropoulos G, Rizos S, Tzanakis N, Zografos G, Gazouli M: Association of the miR-146aC > G, miR-149T > C, and miR-196a2T > C polymorphisms with gastric cancer risk and survival in the Greek population. Mol Biol Rep 2014, 41:1075-1080.

30. Kupcinskas J, Wex T, Link A, Leja M, Bruzaite I, Steponaitiene R, Juzenas S, Gyvyte U, Ivanauskas A, Ancans G, Petrenkiene V, Skieceviciene J, Kupcinskas $L$, Malfertheiner P: Gene polymorphisms of micrornas in helicobacter pylori-induced high risk atrophic gastritis and gastric cancer. PLoS One 2014, 9:e87467.

31. Pu J-Y, Dong W, Zhang L, Liang W-B, Yang Y, LV M-L: No association between single nucleotide polymorphisms in pre-mirnas and the risk of gastric cancer in Chinese population. Iranian Journal of Basic Medical Sciences 2014, 17:128-133

32. Okubo M, Tahara T, Shibata T, Yamashita H, Nakamura M, Yoshioka D, Yonemura J, Kamiya Y, Ishizuka T, Nakagawa Y, Nagasaka M, Iwata M, Arisawa T, Hirata I: Association between common genetic variants in pre-microRNAs and the clinicopathological characteristics and survival of gastric cancer patients. Experimental and Therapeutic Medicine 2010, 1:1035-1040.

33. Tobias A: Assessing the influence of a single study in the meta-analysis estimate. Stata Tech Bull 1999, 8:15-17.

34. Hou Z, Xie L, Yu L, Qian X, Liu B: MicroRNA-146a is down-regulated in gastric cancer and regulates cell proliferation and apoptosis. Med Oncol 2012, 29:886-892.
35. Paik JH, Jang JY, Jeon YK, Kim WY, Kim TM, Heo DS, Kim CW: MicroRNA-146a downregulates NFkappaB activity via targeting TRAF6 and functions as a tumor suppressor having strong prognostic implications in NK/T cell lymphoma. Clin Cancer Res 2011, 17:4761-4771.

36. Bhaumik D, Scott GK, Schokrpur S, Patil CK, Campisi J, Benz CC: Expression of microRNA-146 suppresses NF-kappaB activity with reduction of metastatic potential in breast cancer cells. Oncogene 2008, 27:5643-5647.

37. Hurst DR, Edmonds MD, Scott GK, Benz CC, Vaidya KS, Welch DR: Breast cancer metastasis suppressor 1 up-regulates miR-146, which suppresses breast cancer metastasis. Cancer Res 2009, 69:1279-1283.

38. Jazdzewski K, Murray EL, Franssila K, Jarzab B, Schoenberg DR, de la Chapelle A: Common SNP in pre-miR-146a decreases mature miR expression and predisposes to papillary thyroid carcinoma. Proc Natl Acad Sci U S A 2008, 105:7269-7274

39. Xu W, Xu J, Liu S, Chen B, Wang X, Li Y, Qian Y, Zhao W, Wu J: Effects of common polymorphisms rs11614913 in miR-196a2 and rs2910164 in miR-146a on cancer susceptibility: a meta-analysis. PLoS One 2011, 6:e20471.

40. Qiu LX, He J, Wang MY, Zhang RX, Shi TY, Zhu ML, Mao C, Sun S, Lv FF, Zheng $C L$, Zhu XD: The association between common genetic variant of microRNA-146a and cancer susceptibility. Cytokine 2011, 56:695-698.

41. He B, Pan Y, Cho WC, Xu Y, Gu L, Nie Z, Chen L, Song G, Gao T, Li R, Wang $\mathrm{S}$ : The association between four genetic variants in microRNAs (rs11614913, rs2910164, rs3746444, rs2292832) and cancer risk: evidence from published studies. PLoS One 2012, 7:e49032.

42. Xu Y, Gu L, Pan Y, Li R, Gao T, Song G, Nie Z, Chen L, Wang S, He B: Different effects of three polymorphisms in MicroRNAs on cancer risk in Asian population: evidence from published literatures. PLOS One 2013, 8:e65123.

43. Yin Z, Yan L, Cui Z, Li X, Ren Y, Zhou B: Effects of common polymorphisms rs2910164 in miR-146a and rs3746444 in miR-499 on cancer susceptibility: a meta-analysis. Mol Biol Rep 2013, 40:3003-3013.

44. Song MY, Su HJ, Zhang L, Ma JL, Li JY, Pan KF, You WC: Genetic polymorphisms of miR-146a and miR-27a, H. pylori infection, and risk of gastric lesions in a Chinese population. PLoS One 2013, 8:e61250.

doi:10.1186/s12881-014-0117-2

Cite this article as: Xu et al:: MiR-146a rs $2910164 \mathrm{G} / \mathrm{C}$ polymorphism and gastric cancer susceptibility: a meta-analysis. BMC Medical Genetics 2014 15:117.

\section{Submit your next manuscript to BioMed Central and take full advantage of:}

- Convenient online submission

- Thorough peer review

- No space constraints or color figure charges

- Immediate publication on acceptance

- Inclusion in PubMed, CAS, Scopus and Google Scholar

- Research which is freely available for redistribution 